\title{
Quantitative Trait Loci Contributing to Phencyclidine-Induced and Amphetamine- Induced Locomotor Behavior in Inbred Mice
}

Robert C. Alexander, M.D., Renee Wright, and William Freed, Ph.D.

Phencyclidine (PCP) and amphetamine (AMP) can induce psychotic syndromes in humans, whereas administration of these drugs to mice results in behavioral activation that is influenced by genetic factors. Quantitative trait loci (QTL) underlying genetic differences in response to $P C P$ and AMP in mice were provisionally identified by correlating allelic variation at known marker loci in the BXD series of recombinant inbred (RI) mice and its progenitors (C57BL) 6J and DBA/2J inbred strains) with the locomotor response of each strain to PCP and AMP. Total distance traveled for individual mice from each of the 26 BXD RI and two progenitor strains was measured after injections of normal saline and $7.5 \mathrm{mg} / \mathrm{kg} I P$ injection of PCP. This procedure was repeated after 1 week, using $5.0 \mathrm{mg} / \mathrm{kg}$ of AMP, instead of PCP. Markers significantly $(\mathrm{p}<.01)$ correlated with response to PCP map to murine chromosomes 1, 14, and 15. Response to amphetamine was correlated with markers mapping to chromosomes $4,5,6,8,14$, and 18 . Identification of the QTL underlying PCP-induced and AMP-induced behavior in mice may provide clues into the complicated genetics of psychosis in humans. (C) 1996 American College of Neuropsychopharmacology [Neuropsychopharmacology 15:484-490, 1996]
KEY WORDS: Amphetamine; Inbred mice; Locomotor activity; Model psychosis; Phencyclidine

A variety of compounds can produce psychotic states in humans, although most induce toxic states that poorly correspond to naturally occurring psychotic illnesses (Lipton 1970). Two exceptions are amphetamine and phencyclidine. Behavioral responses to amphetamine include hyperactivity and, in extreme circumstances, features indistinguishable from paranoid schizophrenia, including paranoia and hallucinations (Bell 1965; Snyder et al. 1974). In many respects, however, the phe-

From the Center for Studies of Addiction (RCA), Department of Psychiatry, University of Pennsylvania, Philadelphia; Preclinical Neurosciences Section (RW, WF), Neuropsychiatry Branch, NIMH Neuroscience Center at St. Elizabeths, Washington, DC

Address correspondence to: Robert C. Alexander, M.D., Medical Research Service (151), Department of Veterans Affairs Medical Center, University and Woodland Avenues, Philadelphia, PA 19104.

Received December 20, 1995; revised February 13, 1996; accepted February 28, 1996. nomena induced in humans by phencyclidine (PCP) more closely resemble schizophrenia. Subjects with amphetamine-induced psychosis do not exhibit thought disorder (Ellison and Eison 1983), a primary symptom of schizophrenia, and schizophrenic patients are generally hyporesponsive to the effects of amphetamine (Kornetsky 1976). In contrast, PCP can induce delusions, "loss of ego boundaries," and distortions in body image, hallucinations, thought disorder, agitation, and disturbances in affect (Allen and Young 1978; Domino and Luby 1981; Javitt and Zukin 1991). When PCP was administered to chronic schizophrenic patients, the patients experienced a worsening of their thought disorder, associated with a deterioration in behavior, which resembled an exacerbation of their illness (Domino and Luby 1981). Responses induced by PCP may therefore serve as an alternative and perhaps better neurobiologic model of schizophrenia.

The effects on animals of "psychotomimetic" agents like amphetamine and phencyclidine have been used as 
models for the pathophysiology and biochemistry of schizophrenia. These models are based on the hypothesis that similar mechanisms underlie both their ability to induce aspects of the schizophrenic syndrome in humans and their behavioral and neurobiologic effects in animals. A relatively unexplored aspect of these animal models is their potential to provide clues for molecular genetic studies of schizophrenia.

PCP and amphetamine produce significant increases in spontaneous locomotor activity in the mouse (Oliverio et al. 1973; Freed et al. 1980, 1984). Genetic effects on this PCP-induced and amphetamine-induced stimulation in inbred mice have previously been identified. $\mathrm{BALB} / \mathrm{c}$ mice exhibit a much greater locomotor response to PCP than C57BL/6J mice, whereas six of the $\mathrm{CXB}$ recombinant inbred (RI) strains (derived from a $\mathrm{BALB} / \mathrm{c} \times \mathrm{C} 57 \mathrm{BL} / 6 \mathrm{~J}$ cross) show a continuous distribution of responses consistent with polygenic inheritance (Freed et al. 1984). In addition, significant differences in locomotor response to $\mathrm{PCP}$ between the C57BL/6J, DBA/2J, BALB/CByJ, C57BL/6ByJ, and 11 of the BXD RI (derived from C57BL/6J and DBA/2J cross) strains have been reported (Carney et al. 1992: Dwoskin and Carney 1992). Strain differences in locomotor behavior after amphetamine have been reported for the C57BL/6J, BALB/cBy, and CXB RI inbred mouse strains (Oliverio et al. 1973). Phenotypic differences between inbred strains, when the strains are bred and tested under standard conditions, are interpreted as evidence of genetic influences on the phenotype (McClearn 1991).

Further dissection of the genetic control of PCPinduced or amphetamine-induced behavior in mice is possible through the use of complete RI strain series. RI strains are created by breeding together two inbred strains (the "progenitor strains") and creating new inbred strains from the $\mathrm{F}_{2}$ offspring. This breeding creates a panel of mouse strains, each containing a unique recombination of the chromosomal information from the progenitor strains. Plomin and his colleagues have developed a method of QTL analysis that is specifically designed for use with existing mouse RI strains (Plomin et al. 1991; Gora-Maslak et al. 1991). Briefly, the phenotypic means of the individual RI strains (e.g., the degree of behavioral response to a particular drug) are correlated with markers scored as 0 or 1 , and a productmoment correlation is calculated. For each RI strain, these marker numbers represent the alleles from the two progenitor or parental strains used to create the RI strains; alleles from one parental strain are designated as " 0 " and alleles from the other strain are designated as "1." This method can be used to detect multiple genes (quantitative trait loci or QTL) of varying effect size that influence a given phenotype and can be used even when the progenitor strains do not differ with respect to the phenotypic measure (Plomin et al. 1991). Using this "RI QTL" approach, QTL underlying various responses to substances of abuse, including amphetamine (hyperthermia), alcohol, cocaine, morphine, and nitrous oxide in the BXD/Ty $(\mathrm{C} 57 \mathrm{BL} / 6 \mathrm{~J} \times \mathrm{DBA} / 2 \mathrm{~J}) \mathrm{RI}$ series (Taylor 1978) have been identified (Gora-Maslak et al. 1991; Belknap et al. 1993, 1995; Miner and Marley 1994; Phillips et al. 1995).

In the current study, PCP-induced locomotor behavior was examined in the BXD RI series, which contain 26 inbred strains derived from C57BL/6J (B6) and $\mathrm{DBA} / 2 \mathrm{~J}$ (D2) progenitors. Amphetamine-induced locomotor behavior was also studied in the same animals to determine if genetic factors common to both PCP- and amphetamine-induced behaviors could be identified. Given the extensive linkage homology between human and mouse (Copeland et al. 1993), loci identified in the mouse that influence the response to PCP and/or amphetamine could then be used to suggest candidate regions for human genetic studies.

\section{MATERIALS AND METHODS}

\section{Animals}

Female mice from C57BL/6J, DBA/2J and all 26 existing BXD strains were obtained from the Jackson Laboratory (Bar Harbor, Maine) and group housed for 1 week prior to testing. All mice were maintained on a 12-hour light-dark cycle with food and water available ad lib. The mice were at least 8 to 12 weeks old at the time of testing. All testing and handling procedures were conducted in accordance with the NIH guidelines for the care and use of laboratory animals.

\section{Behavioral Testing}

Total distance traveled for individual female mice from each of the $26 \mathrm{BXD}$ RI ( 7 to 17 mice per strain; mean \pm $\mathrm{SD}=11.3 \pm 2.2)$ and two progenitor strains (D2 $n=13$; B6 $n=14$ ) was measured by placing animals in cages with photocell-activated activity monitors (Digiscan Animal Activity Monitors, Model RXYZCM, Omnitech Electronics, Inc., Columbus, OH; Sanberg et al. 1985). On the day of testing, the animals were transported in their home cages to the testing room, weighed, and placed in the activity monitoring cages. The protocol for testing was as follows: 30 minutes of habituation, followed by an injection of $0.9 \%$ normal saline and $60 \mathrm{~min}$ utes of recording, followed by a $7.5 \mathrm{mg} / \mathrm{kg}$ IP injection of PCP (obtained from Research Biochemicals, Natick, MA) and a final 60 minutes of recording. At the end of the experiment the animals were returned to their home cages. One week later the procedure was repeated, but $5 \mathrm{mg} / \mathrm{kg} d$-amphetamine (obtained from Smith-Kline Research Labs, Philadelphia, PA) was administered instead of PCP. All solutions were injected in a volume of 


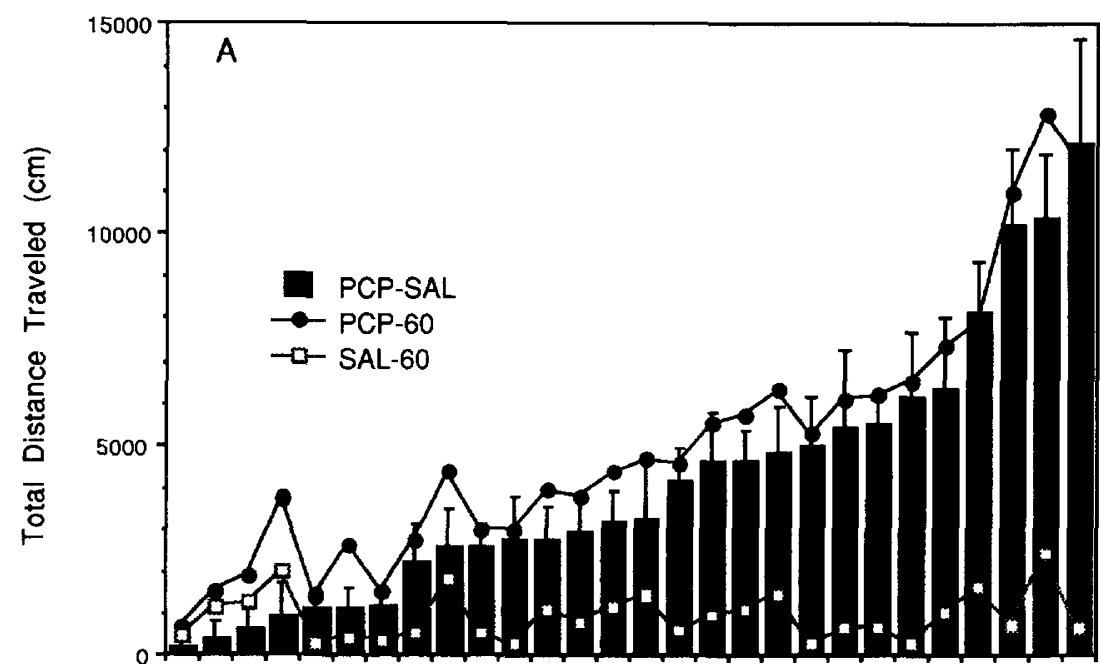

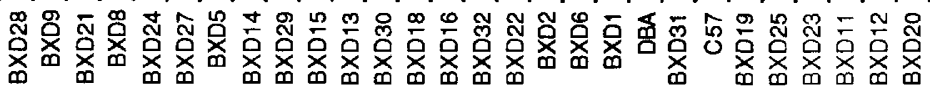

Mouse Strain

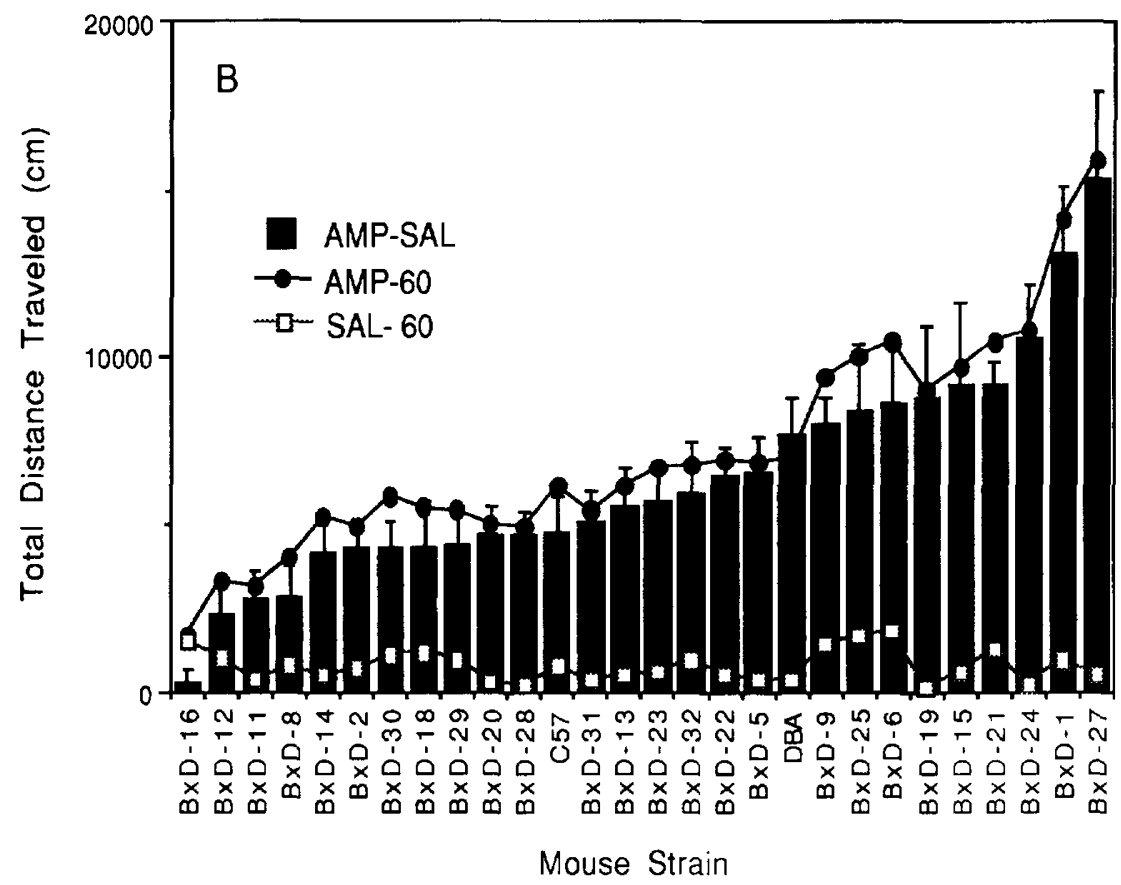

Figure 1. BXD RI strain distributions for total distance traveled in the 1-hour period after IP injection of (A) $7.5 \mathrm{mg} /$ $\mathrm{kg}$ PCP (PCP-60) and (B) $5 \mathrm{mg} / \mathrm{kg}$ amphetamine (AMP-60) (week 1). Bars represent strain means \pm SEM and have been corrected by subtracting the total distance traveled in response to $0.9 \%$ saline (SAL-60) in the hour prior to the administration of either PCP or amphetamine.
$10 \mathrm{ml} / \mathrm{kg}$. The doses of PCP and amphetamine were selected based on the results of previous dose-response experiments (R. Wright et al., unpublished; Grebb et al. 1987). Total distance traveled was calculated for each individual mouse, and the datum used for each strain was the mean of the difference between activity after PCP or amphetamine and activity after saline.

\section{Data Analysis}

One-way ANOVA was used to detect strain differences in response to PCP or amphetamine. Mice in each strain were given sequential identification numbers, and the reliabilities of the phenotypes were estimated by split- ting each strain into two groups (odd and even mouse identification number) and calculating split-half correlations using the Spearman-Brown formula (Plomin and McClearn 1993). Between and within strain variances of the RI strain means were used to estimate heritability and the environmental and additive genetic variances for response to PCP and amphetamine. The additive genetic variance $\left(V_{A}\right)$ can be estimated by using one-half the variance between RI strain means, and the environmental variance $\left(V_{E}\right)$ can be estimated from the average variance within RI strain means (Falconer 1989). Genetic correlations between the locomotor responses to saline, PCP, and amphetamine were assessed using Pearson's $r$ correlations of strain means. 
Table 1. Correlations Estimated Using BXD RI Strain Means for SAL1 (Total Distance Traveled in 1 Hour after $0.9 \%$ Saline Given prior to PCP), PCP (Total Distance Traveled in 1 Hour after $7.5 \mathrm{mg} / \mathrm{kg}$ PCP), PCP-SAL1, SAL2 (Total Distance Traveled in 1 Hour after $0.9 \%$ Saline Given Prior to AMP), and AMP (Total Distance Traveled in 1 Hour after $5.0 \mathrm{mg} / \mathrm{kg}$ Amphetamine)

\begin{tabular}{lccrrc}
\hline & PCP & PCP-SAL1 & SAL2 & AMP & AMP-SAL2 \\
\hline SAL1 & 0.376 & 0.206 & $0.504^{a}$ & -0.221 & -0.299 \\
PCP & & $0.974^{b}$ & -0.006 & -0.299 & -0.295 \\
PCP-SAL1 & & & -0.112 & -0.290 & -0.271 \\
SAL2 & & & & 0.112 & -0.019 \\
AMP & & & & & $0.990^{b}$
\end{tabular}

a $<0.01$.

$b<0.0001$

\section{Quantitative Trait Loci (QTL) Analysis}

The mean activity score (activity after PCP or amphetamine minus activity after saline) for each of the $26 \mathrm{RI}$ were correlated with the allelic distribution of 1388 marker gene loci. The strain distribution patterns of the marker loci were obtained from a compilation of BXD marker loci extracted from the Mouse Genome Database (Manly and Elliott 1991). The B6 alleles were scored as 0, and the D2 alleles were scored as 1. Positive correlations therefore indicate an association between increased locomotor activity and the D2 allele at that locus. Associations between markers and activity scores were examined by using Pearson product-moment correlations as described above, and alpha was set at 0.01 . Multiple regression analyses were used to estimate the amount of genetic variance accounted for by the significant marker associations (Gora-Maslak et al. 1991). The most significant marker on each chromosome was included in these analyses, and the $\mathrm{R}^{2}$ was adjusted downward to take into account the number of markers used in the multiple regression. Whereas the heritability is an estimate of the proportion of the total phenotypic variance that is due to genetic factors, multiple regression analysis provides an estimate of the total amount of the genetic variance that is accounted for by the significant marker associations.

\section{RESULTS}

\section{Response to PCP and Amphetamine}

Total distance traveled in the 1-hour periods after PCP and amphetamine, corrected by subtracting the distance traveled in the hour after administration of saline, for the $26 \mathrm{RI}$ and two progenitor strains are displayed in Figure 1. ANOVA of these data revealed significant strain variations in responses to PCP $(\mathrm{F}=8.07, p<.0001)$ and amphetamine $(\mathrm{F}=5.26, p<.0001)$. The split-half reli- ability for total locomotor activity was $r=0.91$ and $r=0.89$ for PCP and amphetamine, respectively, indicating acceptable reliability of these phenotypes. Using the formula: heritability $\left(h_{2}\right)=V_{A} /\left(V_{A}+V_{E}\right)$, yields heritability estimates of 0.29 and 0.21 for locomotor response to PCP and amphetamine (both corrected for response to saline) respectively. Genetic correlations among locomotor response to saline, PCP and amphetamine are shown in Table 1. Response to PCP was not significantly correlated with response to amphetamine ( $r=-0.299, p=.14)$. The significant correlations were between total locomotor activity after PCP and total locomotor activity after PCP corrected for saline $(r=0.974$, $p<.0001$ ), total locomotor activity after amphetamine and total locomotor activity after amphetamine corrected for saline $(r=0.990, p<.0001)$, and activity after the saline administered prior to PCP and saline administered prior to amphetamine $(r=0.504, p=.0079)$.

\section{QTL Analysis}

Results of the QTL analyses based on total locomotor activity after PCP and amphetamine are shown in Table 2, which lists all markers significantly correlated with the phenotypes at $p<.01$. Markers significantly correlated with response to PCP map to murine chromosomes 1, 14 and 15. These markers account for approximately half of the genetic variance, with an adjusted $R^{2}$ $=0.45$. Response to PCP was positively correlated to the presence of a B6 allele at each of these marker sites. The effect of genotype for the most significant marker on chromosome 1, as well as the markers on chromosomes 14 and 15, on PCP-induced locomotor behavior are shown in Table 3. Response to amphetamine was correlated with markers mapping to chromosomes 4,5 , $6,8,14$ and 18. Markers on these chromosomes accounted for approximately half of the genetic variance, with an adjusted $\mathrm{R}^{2}=0.55$. No common markers were detected for the two phenotypes.

\section{DISCUSSION}

Consistent with previous studies, we found a significant genetic component that underlies the variation in response to PCP and amphetamine between inbred mouse strains. The estimates of heritability of 0.29 for PCP and 0.21 for amphetamine are comparable to heritability estimates derived for other drug-related behaviors in mice, including consumption of $3 \%$ and $10 \%$ ethanol and locomotor activity after repeated ethanol exposure (Phillips et al. 1994, 1995). It is important to note that the RI method can identify QTL even when the heritability is low if the strain means are reliable (Plomin and McClearn 1993). 
Table 2. Significant Correlations between BXD RI Markers and Locomotor Activity after PCP (PCP) and Amphetamine (AMP). Estimated Locations Are in Centimorgans (cM) from the Centromeres and Are Derived from the Mouse Genome Database. Markers Linked at a Probability of $99 \%$, Using the Bayesian Linkage Test in MapManager (Manly and Elliot 1991) Are Grouped and May Indicate a Single Important QTL. The Chromosomal Positions of All Loci That Have Been Localized in the Human Genome Are Shown.

\begin{tabular}{|c|c|c|c|c|c|}
\hline Marker & Chromosome & Location (cM) & Syntenic Human Region & PCP & AMP \\
\hline Mpmv22 & 1 & 100 & & $-0.507^{a}$ & \\
\hline Gstp-rs1 & 1 & 102 & & $-0.507^{a}$ & \\
\hline D1Byu9 & 1 & 102 & & $-0.507^{a}$ & \\
\hline$P m v 21$ & 1 & 102 & & $-0.507^{a}$ & \\
\hline D1Mit17 & 1 & 103 & & $-0.540^{a}$ & \\
\hline$D 4 M c 2$ & 4 & 9 & & & $0.676^{b}$ \\
\hline D4Ncus56 & 4 & 14 & & & $0.548^{a}$ \\
\hline D4Ncus 57 & 4 & 14 & & & $0.535^{a}$ \\
\hline Orm1 & 4 & 29 & $9 q 32$ & & $0.675^{b}$ \\
\hline D4Bir5 & 4 & 29 & & & $0.636^{b}$ \\
\hline D4Mit17 & 4 & 29 & & & $0.630^{a}$ \\
\hline Ptprd & 4 & 38 & & & $0.645^{a}$ \\
\hline$D 4 N d s 7$ & 4 & 39 & & & $0.590^{h}$ \\
\hline Tyrp1 & 4 & 40 & $9 \mathrm{p} 23$ & & $0.590^{a}$ \\
\hline$A d f p$ & 4 & 41 & & & $0.611^{b}$ \\
\hline Iapls $1-10$ & 4 & 41 & & & $0.636^{b}$ \\
\hline If $a$ & 4 & 42 & $9 \mathrm{p} 22$ & & $0.539^{a}$ \\
\hline D4Ncvs 82 & 4 & 43 & & & $0.577^{a}$ \\
\hline D5Ncus 50 & 5 & 68 & & & $0.508^{a}$ \\
\hline$C d 8 a$ & 6 & 32 & $2 \mathrm{p} 12$ & & $0.507^{a}$ \\
\hline Lop1 & 6 & 33 & & & $0.507^{a}$ \\
\hline$D 6 N d s 2$ & 6 & 44 & & & $0.547^{a}$ \\
\hline D6Ncvs51 & 6 & 46 & & & $0.554^{a}$ \\
\hline Gln3-3 & 6 & 47 & & & $0.540^{a}$ \\
\hline Il5ra & 6 & 49 & $3 p 26-p 24$ & & $0.600^{a}$ \\
\hline D6Bir1 & 6 & 50 & & & $0.506^{a}$ \\
\hline D6Nds5 & 6 & 63 & & & $0.597^{a}$ \\
\hline D8Ncus 70 & 8 & 57 & & & 0.648 \\
\hline D8Ncus 69 & 8 & 58 & & & 0.532 \\
\hline Ptprg & 14 & 2 & $3 p 14$ & $-0.530^{a}$ & \\
\hline Ms6-5 & 14 & 19 & & & -0.573 \\
\hline$D 14 N \cos 39$ & 14 & 19 & & & -0.518 \\
\hline$D 15 N c u s 26$ & 15 & 40 & & $-0.539^{a}$ & \\
\hline D18Ncos22 & 18 & 22 & & & -0.525 \\
\hline Slc12a2 & 18 & 27 & & & -0.504 \\
\hline
\end{tabular}


Table 3. Effect of Genotype on Phenotype for PCP-Induced Locomotor Behavior. Mice from the $26 \mathrm{BXD}$ RI and B6 and D2 Progenitor Strains Are Grouped According to Their Genotype. B6 Represents Homozygous for the B6 Allele and D2 Homozygous for the D2 Allele. Values Given Are the Mean Total Locomotor Activity for the 1 Hour Period after a $7.5 \mathrm{mg} / \mathrm{kg} \mathrm{IP}$ Injection of PCP \pm Standard Errors

\begin{tabular}{llll}
\hline Genotype & \multicolumn{1}{c}{ D1Mit17 } & \multicolumn{1}{c}{ Ptprg } & D15Ncvs26 \\
\hline B6 & $6990 \pm 1216$ & $6520 \pm 938$ & $6888 \pm 1113$ \\
D2 & $3516 \pm 504$ & $3485 \pm 401$ & $3625 \pm 440$ \\
\hline
\end{tabular}

We identified three regions of the murine genome that appear to influence response to PCP. A similar QTL analysis of the locomotor response to PCP assessed in six CXB RI strains and both progenitor strains, using data from Freed et al. (1984) revealed significant correlations between this response and marker loci on chromosomes 3, 5, 7, 10, 11, 12, and 16 (Alexander et al. 1994). The absence of any overlap with the present study is possibly due to methodologic differences between the two studies, including differences in PCP dose $(5 \mathrm{mg} / \mathrm{kg}$ versus $7.5 \mathrm{mg} / \mathrm{kg}$, duration of observation ( 30 minutes versus 60 minutes) and apparatus used (Motron-Produkter versus Onmitech). It should be noted, however, that genetic mapping results using different experimental crosses may not be consistent (Lander and Schork 1994). Due to epistatic interactions or fixation of like alleles in the two strains, a QTL may be detected in one cross $(\mathrm{A} \times \mathrm{B})$, but not another cross $(A \times C)$, or it may "disappear" when bred on a different genetic background. It is also difficult to compare the results of Carney et al. (1992) on PCP-induced locomotor response in BXD strains 2, 9, 12, 13, 15, 16, 24, 25, 27, 28 , and 32 , because a different dose of PCP $(3.2 \mathrm{mg} / \mathrm{kg})$ and different methods of assessment were used. Different sets of QTL appear to underlie the responses to PCP and amphetamine, possibly indicating that these drugs elicit increased locomotor activity through separate neurobiologic mechanisms. Whereas the stimulatory action of amphetamine is thought to be the result of its role in facilitating central dopamine transmission (Robinson and Becker 1986), PCP activation appears to be related to interactions between dopaminergic and glutamatergic systems in the brain (Freed 1994).

As noted by Belknap (1992) and others, because of the many correlations that are performed in a QTL analysis of RI data, a number of correlations will be significant due to chance, greatly increasing the Type I error rate. Whereas estimates of the appropriate threshold for statistical significance for RI experiments, derived by using Bonferroni corrections (Belknap 1992), Bayesian statistics (Neumann 1992), or other methods (Lander and Schork 1994), have been proposed, few RI series have enough strains to have sufficient power to "stand alone" at these significance levels. Therefore, QTL analyses of RI series, like the BXD, should be viewed as a "screen" that can be used to suggest candidate map locations. The validity and reliability of these associations can subsequently be confirmed by using other genetic models, including additional RI series, standard inbred strains, $F_{2}$ or backcross populations (Belknap 1992). In the absence of such confirmation, it would be premature to identify candidate genes that lie in the regions listed in Table 2. Belknap et al. (1995) have suggested a two-phase QTL mapping approach, where candidate QTLs are identified in a BXD RI analysis are then confirmed in an $\mathrm{F}_{2}$ population study derived from a $\mathrm{B} 6 \times$ D2 intercross. More recently, Belknap and colleagues (1996) have also proposed that the $p$ values from these experiments could be combined using Fisher's method (Sokal and Rohlf 1981), and a significance threshold recommended by Lander and Schork (1994) and Lander and Kruglyak (1995) for an $\mathrm{F}_{2}$ or backcross experiment (additive, $d f=1)$ should be used $(p=.0001)$. We are currently undertaking such an $\mathrm{F}_{2}$ confirmation experiment of the markers significantly correlated with PCPinduced locomotor behavior.

The genetics of the psychotomimetic action of PCP in humans has not been studied, but there is clearly considerable heterogeneity of the response between individuals. Studies of behavioral reactions in humans after exposure to PCP indicate that $0 \%$ to $19 \%$ develop psychotic reactions (Javitt and Zukin 1991). Whereas the behavioral effects of PCP are species dependent (with hyperactivity in some species and tranquilization in others), both sets of behaviors appear to be mediated through the PCP receptor (Javitt and Zukin 1991). It may be, therefore, that similar neurophysiologic mechanisms underlie a range of behavioral and mental effects in mammals. Given the usefulness of PCP intoxication as a model for schizophrenia, further studies of the genetic influence on PCP response in mice may provide clues to the complicated puzzle of the inherited psychoses.

\section{ACKNOWLEDGMENTS}

The authors gratefully acknowledge the assistance of Magda Giordano, Ph.D. This work was supported by a grant from the Theodore and Vada Stanley Foundation to R.C.A.

\section{REFERENCES}

Alexander RC, Giordano M, Freed W (1994): Genetics of PCP-induced behavior in inbred mice. Schizophr Res 11:143

Allen RM, Young S (1978): Phencyclidine-induced psychosis. Am J Psychiatry 135:1081-1084 
Belknap J (1992): Empirical estimates of Bonferroni corrections for use in chromosome mapping studies with the BXD recombinant inbred strains. Behav Genet 22:677684

Belknap J, Metten P, Helms M, O'Toole S, Angeli-Gade S, Crabbe J, Phillips T (1993): QTL applications to substances of abuse: Physical dependence studies with nitrous oxide and ethanol in BXD mice. Behav Genet 23:213-222

Belknap J, Mitchell S, O'Toole L, Helms M, Crabbe J (1996): Type I and type II error rates for quantitative trait loci (QTL) mapping studies using recombinant inbred strains. Behav Genet (in press)

Belknap J, Mogil J, Helms M, Richards S, O'Toole L, Bergeson S, Buck K (1995): Localization of chromosome 10 of a locus influencing morphine analgesia in crosses derived from C57BL/ 6 and DBA/2 strains. Life Sci 57:PL 117-124

Bell D (1965): Comparison of amphetamine psychosis and schizophrenia. Br J Psychiatry 3:701-707

Carney J, Seale TW, Bardo M, Dwoskin L (1992): Qualitative and quantitative difference in the behavioral effects of phencyclidine in inbred mice. In Kamemka J-M, Domino EF (eds), Multiple Sigma and PCP Receptor Ligands: Mechanisms for Neuromodulation and Neuroprotection? Ann Arbor, NPP Books, pp 607-618

Copeland NG, Jenkins NA, Gilbert DJ, Eppig JT, Maltais LJ, Miller JC, Dietrich WF, Weaver A, Lincoln SE, Steen RG, Stein LD, Nadeau JH, Lander ES (1993): A genetic linkage map of the mouse: Current applications and future prospects. Science 262(5130):57-66

Domino EF, Luby ED (1981): Abnormal mental states induced by phencyclidine as a model of schizophrenia. In Domino EF (ed), PCP (Phencyclidine): Historical and Current Perspectives, Ann Arbor, NPP Books, pp 401418

Dwoskin L, Carney J (1992): Genetic isolation of in vivo and in vitro PCP responsiveness. In Kamemka J-M, Domino EF (eds), Multiple Sigma and PCP Receptor Ligands: Mechanisms for Neuromodulation and Neuroprotection? Ann Arbor, MI, NPP Books, pp 850-877

Ellison GD, Eison MS (1983): Continuous amphetamine intoxication: An animal model of the acute psychotic episode. Psychol Med 13:751-761

Falconer DS (1989) Introduction to Quantitative Genetics. New York, Longman Scientific and Technical

Freed W (1994): Glutamatergic mechanisms mediating stimulant and antipsychotic drug effects. Neurosci Biobehav Rev 18:111-120

Freed W, Weinberger D, Bing L, Wyatt RJ (1980): Neuropharmacologic studies of phencyclidine (PCP)-induced locomotor stimulation in mice. Neuropharmacology 23:175-181

Freed W, Crump S, Jeste D (1984): Genetic effects on PCPinduced stimulation in recombinant inbred strains of mice. Pharmacol Biochem Behav 21:159-162

Gora-Maslak G, McClearn G, Crabbe J, Phillips T, Belknap J, Plomin R (1991): Use of recombinant inbred strains to identify quantitative trait loci in psychopharmacology. Psychopharmacology 104:413-424
Grebb J, Shelton R, Freed W (1987): Ditiazem or verapamil prevent haloperidol-induced apomorphine sensitivity in mice. J Neural Transm 68:241-255

Javitt D, Zukin S (1991): Recent advances in the phencyclidine model of schizophrenia. Am J Psychiatry 148:13011308

Kornetsky C (1976): Hyporesponsivity of chronic schizophrenic patients to dextroamphetamine. Arch Gen Psychiatry 33:1425-1428

Lander ES, Kruglyak L (1995): Genetic dissection of complex traits: Guidelines for interpreting and reporting linkage results. Nature Genet 11:241-247

Lander ES, Schork N (1994): Genetic dissection of complex traits. Science 265:2037-2048

Lipton MA (1970): The relevance of chemically induced psychoses to schizophrenia. In Efron DH (ed), Psychotomimetic Drugs, New York, Raven Press

Manly KF, Elliott RW (1991): RI manager, a microcomputer program for analysis of data from recombinant inbred strains. Mammalian Genome 1:123-126

Neumann P (1992): Inference in linkage of multifactorial traits using recombinant inbred strains of mice. Behav Genet 22:665-676

Oliverio A, Eleftheriou B, Bailey D (1973): Exploratory activity: Genetic analysis of its modification by scopolamine and amphetamine. Physiol Behav 10:893-899

Phillips T, Crabbe J, Metten P, Belknap J (1994): Localization of genes affecting alcohol drinking in mice. Alcoholism Clin Exp Res 18:931-941

Phillips TJ, Huson M, Gwiazdon C, Burkhart-Kasch S, Shen E (1995): Effects of acute and repeated ethanol exposures on the locomotor activity of $\mathrm{BXD}$ recombinant inbred mice. Alcohol Clin Exp Res 19:1-10

Plomin R, McClearn G (1993): Quantitative trait loci (QTL) analyses and alcohol related behaviors. Behav Genet 23:197-211

Plomin R, McClearn GE, Gora-Maslak G, Neiderhiser JM (1991): Use of recombinant inbred strains to detect quantitative trait loci associated with behavior. Behav Genet 21:99-116

Robinson T, Becker J (1986): Enduring changes in brain and behavior produced by chronic amphetamine administration: A review and evaluation of animal models of amphetamine psychoses. Brain Res Rev 11:157-198

Sanberg PR, Hagenmayer SH, Henault M (1985): Automated measurement of multivariate locomotor behavior in rodents. Neurobehav Toxicol Teratol 7:87-94

Snyder S, Bannerjee S, Yamamura H, Greenberg D (1974): Drugs, neurotransmitters, and schizophrenia: Phenothiazines, amphetamine, and enzymes synthesizing psychotomimetic drugs and schizophrenia research. Science 184:1243-1253

Sokal R, Rohlf F (1981): Biometry, San Francisco, CA, Freeman, pp 779-782

Taylor B (1978): Recombinant inbred strains: Use in gene mapping. In Morse HC (ed), Origins of Inbred Mice. New York, Academic Press, pp 423-438 